\title{
Achievement Goals and Student Well-Being
}

\author{
Avi Kaplan \\ Ben-Gurion University of the Negev, Be'er-Sheva, Israel \\ and \\ Martin L. Maehr \\ University of Michigan
}

\begin{abstract}
This study is concerned with the role that achievement goals may play in facilitating the psychological well-being of students. Specifically, we build on "goal theory" analysis of adaptive behavior in examining the relationship between task and ego goals, perceptions of school emphases on task and ego goals, and indices of well-being and disruptive behavior. Generally, task goals and perception of the school as emphasizing task goals were related to positive psychological well-being, and ego goals and perceiving the school as emphasizing ego goals were related to negative psychological well-being. This pattern was found for both African American and Euro-American students. However, path analyses pointed to possible different processes as operating for the African Americans and the Euro-Americans in the sample. ๑ 1999 Academic Press
\end{abstract}

Over the past decade or so, motivational research has focused extensively on the role that purpose plays in shaping attitude and the intensity and quality of behavior (cf. Ames, 1992; Anderman \& Maehr, 1994; Urdan \& Maehr, 1995 for recent reviews). Primary attention has been given to two goals, Task and Ego, ${ }^{1}$ and a large body of information has evolved that is related to the effects of these goals on learning and achievement in particular. When, for example, individuals engage in an activity with the purpose of developing skills, gaining competence, and promoting understanding — task goal- they are more likely to invest in the task. More importantly, when they invest

The authors thank Paul Pintrich and Carol Midgley for their helpful comments.

Address correspondence and reprint requests to Avi Kaplan, 1225, Department of Education, Ben-Gurion University of the Negev, Be'er-Sheva 84105, Israel. E-mail: akaplan@ @gumail. bgu.ac.il.

${ }^{1}$ Other theorists have used different names for these goals. "Task focused goals" are sometimes referred to as "mastery goals" or "learning goals" and "ego focused goals" are sometimes referred to as "ability goals" or "performance goals" (Ames, 1992; Anderman \& Maehr, 1994; Dweck, 1986; Meece \& Holt, 1993). 
they are likely to invest in a qualitatively different fashion. Briefly, they use more adaptive learning strategies and go about the task while self-regulating their behavior. There is also evidence that when engaged under a task goal, students will more likely exhibit thoughtful and creative engagement.

In contrast, engagement in an activity while pursuing self-enhancing social comparison-ego goals - has been associated with maladaptive learning strategies, lack of venturesomeness in learning, a focus on quick solutions rather than reflective reasoning, as well as a more negative view of the task to be done. These associations, however, were found mostly for students with low perceived ability. For students with high perceived ability, ego goals seem to be associated with some negative (e.g., passing opportunities) but some positive outcomes (Dweck \& Leggett, 1988). The breadth and depth of this literature is impressive as also is the degree of convergence around the fundamental learning patterns associated with these two basically different purposes in approaching learning tasks (cf. Ames, 1992; Dweck \& Leggett, 1988; Pintrich, Marx \& Boyle, 1993; Urdan, 1997 for recent reviews on goals and adaptive learning).

\section{GOALS AND WELL-BEING}

While the role of goals has been primarily demonstrated in the realm of learning and achievement, there is a preliminary basis for suggesting that task and ego goals influence a wide range of action, thought and affect, including those associated with general well-being-general self-evaluations and patterns of behavior, coping, and emotion. First, as goals affect learning and achievement they are likely also to contribute to adolescents' well-being. Schools and school achievement are obviously important, at least in a general way, to adolescents' self-evaluations and well-being. Less immediately obvious is that holding task and ego goals is likely to trigger different behavioral, coping and emotive processes. Specifically, ego goals (as the label implies) differ from task goals in the degree to which students appraise events in relation to the self - in particular, to one's perceived competence. In achievement situations this may result in cases where students construct an objective of outperforming or besting others. Success, therefore, is evaluated in social comparison terms. In terms of developing self-esteem, this is a decidedly hazardous situation. By definition, success is a limited commodity. Only a few, at best, can win a competitive game. Most end up "losers,' a factor that not only influences their attitude toward school but probably also their sense of self-esteem. Even "winners," to remain winners, may engage in cognitive and behavioral strategies that are counter to long-term growth and wellness (cf. Covington, 1992). The risk of making mistakes publicly deters those individuals from taking advantage of opportunities to increase competence (Elliott \& Dweck, 1988).

The emotive aspect triggered by goals is most apparent when confronting 
a stressful event. Dweck (1986; Dweck \& Leggett, 1988), for example, found that students who adopted ego goals, and especially those with low perceived ability, tended to manifest a "helpless" pattern when they encountered failure. These students reported negative self-evaluations, displayed negative affect, and disengaged from the task. In contrast, students who pursued task goals manifested a "mastery" pattern. These students viewed the situation as a challenge, maintained an optimistic orientation and positive affect, and attempted to change their problem solving strategies. Importantly, as the focus in task goals is not on the self, task-oriented students manifested the mastery pattern regardless of their level of perceived ability. It is reasonable to assume that, in the long term, such differing experiences of failure would influence students' well-being more generally, beyond the situational affect in a particular classroom. The focus on social comparison for self-enhancement has in fact been found to be associated with a number of coping strategies that may be maladaptive not only for achievement but general wellbeing (cf. Covington, 1992).

\section{GOALS AMONG AFRICAN AMERICAN ADOLESCENTS ${ }^{2}$}

The heightened concern with self-evaluation and social comparison that accompanies a pursuit of ego goals may be especially damaging to the academic attitudes and well-being of African American students. Graham (1994) has made the suggestion that views of self are likely to play a different role for African American than Euro-American groups. She, as well as others, contends that the sources for judgments about one's self may be different within the two groups. African American students, for example, maintain high self-concept in situations (e.g., failure) where Euro-American students' evaluations of self decrease. Similarly, Ogbu $(1981,1992)$ has presented a strong case for the argument that schools, in particular, may not hold the same power over African American and Euro-American students. And, Steele and his colleagues (Steele, 1992; Steele \& Aronson, 1995) hypothesize that, in the long run, being aware of the existence of a negative stereotype about one's group might lead to diminished interest in academics and to protective disidentification with school achievement. This argument has been echoed to varying degree and in different form by others (see, e.g., Covington, 1992).

However, Steele and Aronson (1995) also contend that African American students are sensitive to social comparison in a manner that is different from

${ }^{2}$ Gender is not a focus in this paper. However, we acknowledge the different experiences of various groups within the African American student and Euro-American student population. Thus, while not providing a substantive discussion and analysis of gender differences, analyses pertaining to the different experiences of African American and Euro-American students in the present paper involve statistical control of gender variance. 
Euro-American students. In addition to the concern with the individual self, minority students are also concerned with a collective self. Social comparison poses a risk not only to evaluations of the individual's abilities but has the potential of confirming a negative ethnic stereotype-a "stereotype threat." Such a concern, they find, interferes with performance.

Academic situations can elicit this concern among African American students. Steele and Aronson believe, for example, that the act of taking an academic test is enough to induce such a concern. They assert that "for Black students who care about the skills being tested-that is, those who are identified with these skills in the sense of their self-regard being somewhat tied to having them-the stereotype loads the testing situation with an extra degree of self-threat, a degree not borne by people not stereotyped in this way"' (pp. 798-799). It is reasonable to assume that African American students who pursue ego goals, and who are therefore concerned with demonstrating competence, might experience stronger anxiety that will contribute to lowered performance, negative affect, and disruptive behavior.

While it seems logical that goals may differentially influence not only further adaptive learning but also adaptive patterns and behavior more generally, this possibility has to date been given only scant attention. Considering the influence of goal emphases and orientations on well-being may not only serve to expand the applicability of goal theory but provide a productive perspective on the sources of students' well-being and behavior.

\section{THE EXPERIENCED ENVIRONMENT AND GOAL ORIENTATION}

The present study focuses on students' perceptions of the goal emphases in the school-their interpretation of the practices and events in terms of success as personal improvement or as a competitive social comparisonand how these influence students' goal pursuit, self-perceptions, and general well-being. This perspective contends that in perceiving goal emphases, students are appraising situations in school as posing risk to self (in the case of ego goals combined with low perceived ability) or as not relevant to self (in the case of task goals) (cf. Lazarus, 1993). What may be particularly attractive about this perspective on well-being is the emphasis placed on context and the potential that this holds for intervention and prevention. Whereas personal goals can influence appraisal of situations as emphasizing one goal over another, a significant and growing portion of the goal theory literature has attended to the possibility that goal adoption is in part a social constructive process (Maehr, Midgley, \& colleagues, 1996; Nichols, 1989, 1992). First, it has been found that contexts, school contexts in particular, vary in ways that seem to lead individuals to construe the purpose, meaning, and the goals of the situation differently. Multiple laboratory studies have established the relation of certain manipulations of the context and adoption of different goals (Dweck \& Leggett, 1988). And a naturalistic intervention 
in classrooms indicated the relation between changes in educational practices and goal adoption (Ames, 1990). In various other studies, students were found to adopt different goals in different classrooms, and this adoption has been shown to be related to their perceptions of goals emphasized as well as to specific instructional and management practices employed by teachers, such as how they group, evaluate, and recognize children, and how they organize the learning task (Ames \& Archer, 1988; Meece, Blumenfeld, \& Hoyle, 1988; Meece, 1991; Midgley et al., 1995; Nolen, 1988; Nolen \& Haladyna, 1990).

Parallel to research at the classroom level, research on school climate and culture indicates that schools as a whole reflect different goal emphases (Kaplan \& Maehr, 1997; Krug, 1989; Maehr, 1991; Maehr \& Fyans, 1989; Maehr \& Midgley, 1991, 1996). Just as the smaller unit of the classroom has been found to define learning, it now appears that the larger unit of the school may likewise define purposes and therewith have a pervasive influence on student beliefs and behaviors. Moreover, intervention research has shown that emphases of task and ego goals are closely tied to specific school policies and practices (Maehr et al., 1996) and that students' perceptions of goal emphases as well as their goal adoption are related to changes in these practices (Anderman, Maehr, \& Midgley, in press). In a recent study, Roeser, Midgley, and Urdan (1996) supported the relations between students' perceptions of the goals that are emphasized in school; students' goal pursuit; and academic, cognitive, and affective outcomes. In particular, students' perceptions of the school as emphasizing task goals were mediated by students' pursuit of task goals and were positively associated with higher academic self-efficacy and positive school affect. Students' perceptions of the school as emphasizing ego goals were mediated by their pursuit of ego goals and were associated with academic self-consciousness.

In sum, the general emphases on task and ego goals that students perceive in schools and the goals they adopt appear to be important factors in students' school behavior and may have broader implications for adaptive development. Given current concerns with the schools, particularly those attended by young adolescents (Carnegie Council on Adolescent Development, 1989; Eccles et al., 1993), the time seems especially ripe to examine this relationship.

\section{SPECIFIC PURPOSES OF THE STUDY}

This study is the heir to extensive theoretical and practical work devoted to the understanding of the sources and effects of goals. In the first instance, our objective was to extend the applicability of goal orientation theory to adaptive patterns of behavior and orientations more generally. We tested the general hypothesis that perceptions of school emphasis on task and ego goals and the goals adopted by students are associated with different expressions 


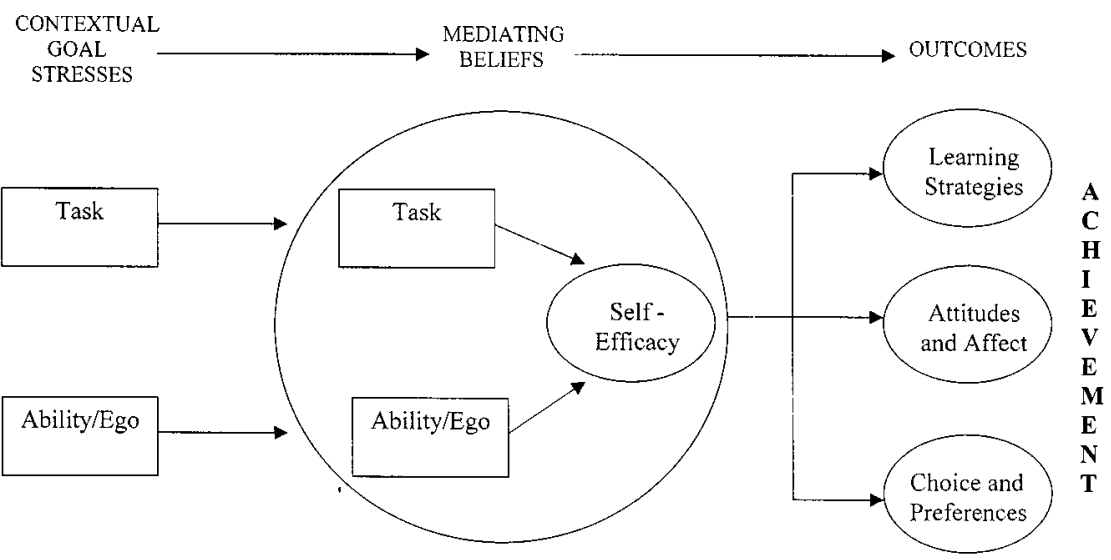

FIG 1. Schematic representation of the goal theory model. Adapted from Anderman and Maehr (1994). Copyright [1994] by the American Educational Research Association; reproduced with permission from the publisher.

of well-being. Specifically, we hypothesized that perceived school emphasis on task goals and personal task goals will be related to a positive pattern of student well-being, whereas perceived emphasis on ego goals and personal ego goals will be related to a negative pattern of student well-being. Another feature of the study, however, was a focus on the possible differences in patterns that exist in the case of African and Euro-American students. We expected to find African American students who pursue ego goals as likely to report negative affective and behavioral experiences as Euro-American students. In addition, however, we also expected to find African American students' self-processes as playing a more central and stable role in determining their academic experience and as less influenced by their behavior and orientations.

The study was framed by a theoretical model suggested by Anderman \& Maehr (1994) and outlined in Fig. 1. The model argues for the mediating role of goals and self-processes between perceptions of the school environment and affective and behavioral outcomes. This model was supported by Roeser et al. (1996). However, attention will be given to limitations of this model and to necessary revisions needed, especially in exploring the patterns exhibited in the case of self processes among African American and EuroAmerican groups.

\section{METHOD}

\section{Participants}

The sample consisted of 168 students of which 91 were girls $(54.2 \%)$ and 77 were boys $(45.8 \%)$. All participants were in the sixth grade and in their first year after a transition to 
TABLE 1

Measures and Descriptive Statistics

\begin{tabular}{lcrl}
\hline Variable & Mean & $S D$ & $\alpha$ \\
\hline Personal task goals & 3.41 & .92 & .80 \\
Personal ego goals & 3.20 & 1.24 & .84 \\
Perception of school emphasis on task goals & 3.92 & .80 & .83 \\
Perception of school emphasis on ego goals & 2.64 & .92 & .75 \\
Perceived academic efficacy & 3.79 & .88 & .84 \\
Emotional tone & 3.73 & .71 & .78 \\
Peer relationships & 3.89 & .75 & .79 \\
Impulse control & 3.33 & .85 & .79 \\
Affect at school & 2.96 & .92 & .82 \\
Perceived disruptive behavior & 1.99 & .99 & .83 \\
\hline
\end{tabular}

middle school. Of the total, 91 of the students (54.2\%) were Euro-Americans, 66 (39.3\%) were African Americans, and 11 (6.5\%) were of other ethnic backgrounds. ${ }^{3}$ This composition reflects a similar distribution of race in the community. The school is the sole middle school in a small southeastern Michigan urban district. The community is of a working class, mostly employed by the automobile industry. The median income for household in the community is approximately $\$ 30,000$. Among the 3900 students in the district, close to $24 \%$ live in poverty. The middle school enrolls around 700 students each year of which approximately $50 \%$ are eligible for free or reduced fee lunch. Eligibility for lunch privileges is decided based on a review of the family's financial resources which follows the federal guidelines. The students surveyed in the present study achieved an average of $37.5 \%$ on the math part and $34.7 \%$ on the reading part of the Michigan Standardized Test Panel (MEAP) the year after the study.

All the sixth grade students in the school received permission slips to be filled out by their parents/guardians. Nine students were denied permission by their guardians and did not participate in the study. Twenty-two students who were assigned to special education classes did not participate as well. Of the rest, 37 students were missing the day of the survey, refused (for unknown reasons) to fill out the survey, or filled out only parts of the survey. The final number of participants, 168 students, on whose responses the analysis was conducted is $72 \%$ of the total number of sixth grade students in this school.

\section{Procedure}

The subjects responded to a 90 -item survey which was administered by research assistants in the students' classes. The teacher was present in the room but was not involved with administering the survey. Students were assured that their answers would be kept confidential. The items were read aloud and time was given for the students to respond. The students were encouraged to ask for clarification regarding unclear items. The time it took to fill the survey was approximately $45 \mathrm{~min}$.

\section{Measures}

A summary of the measures employed and their descriptive statistics is presented in Table 1. All items used appear in the Appendix. The final analyses were conducted on 10 scales

\footnotetext{
${ }^{3}$ The other ethnic backgrounds included Arab Americans, Asian Amerians, and Hispanics.
} 
comprised of 71 items. The remaining items belong to 4 scales that were not used in the present analysis. The response scale for all the items in the survey was a 5-point Likert scale with anchors of 1- "not at all true of me" to 5-"very true of me."

Psychological well-being was treated in this study as a phenomenological organization of students' emotional, cognitive, and behavioral experiences. This construct is known to be composed of various dimensions (cf., Kazdin, 1993; Veit \& Ware, 1983) and was therefore assessed with a variety of measures. The measures included students' report on their general emotional tone as well as more specific affect they experience in school, general behavioral control as well as disruptive behavior in the class, students' perceptions of their social relationship with peers, and perceptions of academic efficacy.

General well-being. General emotional tone, perceptions of relationship with peers, and general behavioral control were assessed with scales adopted from the Self-Image Questionnaire for Young Adolescents (SIQYA), developed by Petersen et al. (1984). The SIQYA was found to be highly correlated with the Rosenberg Self-Esteem Inventory (SEI) which is a well validated measure of self-esteem. It was also found to distinguish between groups who reported four kinds of mental health problems from subjects who did not report these problems, and was found to distinguish between adolescents with a poor family relationship and adolescents whose parents were married and did not report discord (Petersen et al., 1984). Three out of 9 scales in the SIQYA were used in the present study. The scales are labeled Emotional Tone, Peer Relationship, and Impulse Control. All the items in these three scales-11, 9, and 7, respectively - were used in the present study. The other scales were not used as some (Family Relationships; Body Image) seemed unrelated to the purpose of the study, others (Psychopathology) included items asking for information evaluated to be sensitive and unnecessary for the present study, and yet others (Mastery and Coping; Superior Adjustment; VocationalEducational Goals) included items that conflicted with the goal and academic efficacy constructs (e.g., "If I put my mind to it, I can learn almost anything"; "I am a superior student in school"; "I enjoy learning new things"'). Therefore, with the realization that use of only part of the measure might compromise validity, we nevertheless chose to use only the three scales mentioned above. The validity of the particular scales was examined in the present study by their correlations with scales from other measures that tap on school related affect and behavior as reported below. Petersen et al. report that the three scales chosen manifested satisfactory internal consistency (Emotional Tone: boys $\alpha=.81$, girls $\alpha=.85$; Peer Relationship: boys $\alpha=.85$, girls $\alpha=.81$; Impulse Control: boys $\alpha=.72$, girls $\alpha=.76$ ). In the present sample the three scales manifested internal consistency of $.78, .79$, and .79 , respectively.

\section{School-Based Measures}

Six of the scales used in the present study were adopted from the Patterns of Adaptive Learning Survey (PALS) by Midgley, Maehr, and Urdan (1993). Scales in PALS were developed during a 5-year period and tested with various samples of young and middle adolescents from various ethnic and socioeconomic backgrounds (Midgley et al., 1998). PALS includes multiple scales which were developed by several researchers. The validity of each scale was established separately (see Midgley et al., 1998). As the outcome variables of the study concern general well-being, and as the focus of the paper is on the effect of the school as a whole, measures of school-related variables were general rather than domain-specific.

School-related affect. Affective experiences in school were measured using the Positive Affect at School and Negative Affect at School scales constructed by Wolters, Garcia, and Pintrich (1992) and listed in PALS. Items in the two scales factor analyzed together and therefore were combined to create a 7-item Affect at School scale which combined the two aspects 
of the affective experience. Items measuring the positive affect were used by Roeser et al. (1996) and manifested substantial internal consistency $(\alpha=.81)$. These items in combination with the negative affect items manifested in the present study in internal consistency of $\alpha=$ .82 .

Perceived academic efficacy. A 6-item scale measuring students' perceived academic efficacy to master the material taught in school was also adopted from PALS. This scale was used by Roeser et al. (1996) as well as by Midgley et al. (1998) and manifested internal consistency of $\alpha=.86$ and $\alpha=.81$, respectively. In the present study the scale manifested internal consistency of $\alpha=.84$.

Personal and perceived emphasis of achievement goals. The scales measuring personal and perceived achievement goals were adopted from PALS (Midgley et al., 1993). The scales were used by Roeser et al. (1996) and were found to have internal consistency ranging from $\alpha=$ .62 to .81 . Midgley et al. (1998) tested the reliability and validity of the personal goals and found them to be valid and reliable. In the present study all the scales manifsted satisfactory internal consistency (perceived task emphasis: $\alpha=.83$; perceived ego emphasis: $\alpha=.75$; personal task goals: $\alpha=.80$; personal ego goals: $\alpha=.84$ ).

Self-report of disruptive behavior. A 5-item scale measuring self report of disruptive behavior was constructed for this study. The scale attempts to operationalize students' perceptions of themselves as disruptive and therefore taps on self-perceptions in relation to classroom norms and regulations. Students that perceive themselves as disruptive are likely to feel inadequate in the classroom-a feeling that might result in or be the consequence of alienation. Such students may indeed be a source of disruption to the class. The internal consistency of this scale in the present study was $\alpha=.83$. These perceptions were positively correlated $(r=.44, p<.01)$ with the number of discipline slips students had in their records. Since students do not receive discipline referrals on each disruptive event, many students did not have referrals, and the measure of discipline referrals was highly skewed (Skewness $=3.89$ ). The self-report scale seemed to be a fairly accurate indicator of disruptive behavior and did not exhibit some of the negative properties of discipline referrals. Furthermore, the focus of the present paper on self-image as an indicator of well-being merits the emphasis on students' self-perceptions of their disruptive behavior. We therefore decided to use this measure in all further analyses.

Information on achievement, socioeconomic status (SES), and ethnicity was collected from school records. Achievement was measured by the students' GPA and was obtained from students' report cards. It was scored on a continuous scale (0.0-4.0) as it appeared in the report cards. Administrative restrictions prevented access to families as a source of SES and ethnicity information. A separate study conducted in the district indicated that students' selfreport of parents' education was not a valid estimate of SES. SES was, therefore, coded based on students' eligibility for free or reduced fee lunch. Ethnicity was coded based on the coding system of the school.

The self-image, perceived academic efficacy, and affect at school scales were coded so that a high score means a positive outcome on the measure. The disruptive behavior scale was coded so that a high score means perceptions of high disruptive behavior. The achievement goals variables were coded so that a high score means having high goals as implied by the construct name.

\section{RESULTS}

The results are presented in five parts. First, we present descriptive data, including intercorrelations of all scales and constructs and summarize the results of a series of analyses focused on the possible role of SES as a moderator of psychological well-being and achievement. A second series of analy- 
ses examined the relationship of personal goals to well-being taking into account possible SES, ethnicity and gender differences. A third series considered the source of students' well-being in the "psychological culture" of school; that is, in the kind of climate or psychological environment that existed for students; again while considering possible demographic differences. A fourth series of analyses examined the relationships between personal goals and well-being and between perceptions of school emphasis on goals and well-being separately for African American and Euro-American students. Finally, using path analysis we explore the conceptual model proposed by Anderman and Maehr (Fig. 1) of school effects on Well-Being and seek differences in the case of African American and Euro-American students.

\section{Part 1: Interrelationships among Variables}

Table 2 reports zero order correlations among the variables. The general well-being and the Affect at School variables were positively correlated among themselves. The disruptive behavior variable was negatively correlated with the general well-being and affect variables. The two exceptions to this pattern were "peer relationship" and "impulse control," and Peer Relationship and Disruptive Behavior which were not significantly correlated. Perceptions of academic efficacy were positively correlated with all the general well-being and affect variables, and negatively correlated with the perceptions of disruptive behavior. GPA was positively correlated with impulse control, affect at school, and perceptions of academic efficacy, and negatively correlated with perceptions of disruptive behavior. These correlations provide indication of concurrent and convergent validity for the general well-being scales.

Personal task and ego goals were not correlated, incidentally contributing further evidence in support of the theoretical assumption that these two goals are not merely polar opposites but rather orthogonal constructs (Meece \& Holt, 1993). Perceptions of the school as emphasizing task goals were positively and highly correlated with holding task goals. Perceptions of the school as emphasizing ego goals were positively correlated with holding ego goals. The perceptions were negatively correlated with each other.

In part as a prelude to the more focused consideration of ethnicity and adaptive school behavior, we systematically examined the relationship of socioeconomic status (SES) of all subjects in reference to all variables and their interrelationships. A one way analysis of variance (ANOVA) revealed a significant difference $\left(F=3.19, p<.04, R^{2}=.04\right)$ among the three groups (free lunch, reduced lunch, no privileges) on GPA. The Bartlett-Box test supported the existence of homogeneity of variance $(F=.29, p=.75)$. Table 3 presents the GPA means for the three groups. The Scheffe range test indicated that the free lunch group had a significantly lower GPA than the group with no lunch privileges. ANOVAs testing for differences among 


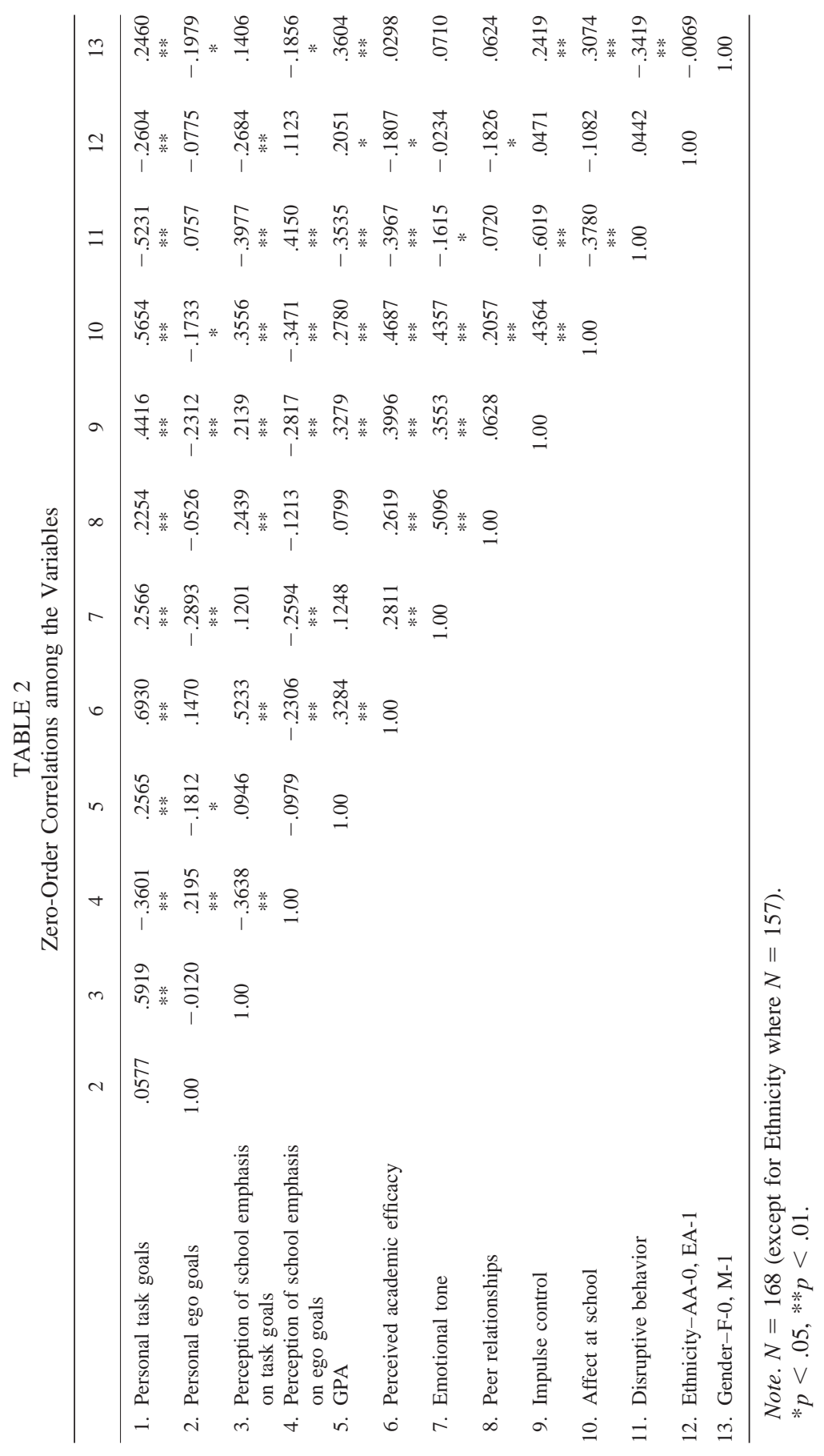


TABLE 3

GPA Means of SES Groups

\begin{tabular}{lcc}
\hline & $N$ & Mean GPA \\
\hline Whole sample & $162 *$ & 2.64 \\
Free lunch & 47 & 2.37 \\
Reduced lunch & 18 & 2.70 \\
No privileges & 97 & 2.76 \\
\hline
\end{tabular}

* Six cases had missing data.

the SES groups on other measures, including achievement goals, perceptions of academic efficacy, affect at school, and perceptions of the goals emphasized in the school, were not significant. SES was not found to interact with ethnicity in affecting GPA. A chi-square test indicated that SES differences among the ethnic groups was not significant. For the following analyses, a dummy variable was created for SES. Since the significant difference was apparent between the free lunch group and the no-privileges group, the dummy variable included only these two groups with free lunch as 0 and no-privileges as 1 .

\section{Part 2: Goals and Well-Being}

In order to begin to determine, based on the theoretical explications of the Anderman and Maehr (Fig. 1) model, whether or how personal goals might impact well-being, we conducted a series of hierarchical multiple regressions employing the psychological measures of well-being as well as GPA as dependent variables. Dummy variables representing SES (free lunch $=0$, no-privileges $=1$ ), ethnicity (African Americans $=0$, Euro-Americans $=1$ ), and gender (Girls $=0$, Boys $=1$ ), were first entered. In a second step, personal task goals and personal ego goals were entered as a block into the equation. In a third step, the interaction terms of personal goals and GPA and personal goals and perceived academic efficacy were entered in analyses testing effects on general well-being, affect at school, and disruptive behavior. This last step follows the findings of experimental studies (e.g., Dweck \& Leggett, 1988) which would predict different patterns of outcomes for students with ego goals and different levels of perceived academic efficacy and achievement. Variables were centered prior to the formation of the interaction terms to avoid possible multicolinearity (Aiken \& West, 1991). Table 4 presents Beta values of personal goals as predictors of the well-being measures and of GPA after controlling for SES, ethnicity, and gender. Beta values of the demographic variables are reported only when significant.

A finding of major interest was that holding task goals was found to be a significant positive predictor for all measures of well-being and GPA and a significant negative predictor for perceptions of disruptive behavior. Hold- 
TABLE 4

Personal Goals as Predictors of Well-Being

\begin{tabular}{lcccc}
\hline & Task goals & Ego goals & Demographics & $R^{2}$ \\
\hline Emotional tone & $0.26^{* * *}$ & $-0.30^{* * *}$ & & 0.15 \\
Peer relationships & $0.17^{* *}$ & -0.13 & & 0.08 \\
Impulse control & $0.42^{* * *}$ & $-0.22^{* *}$ & & 0.27 \\
Affect at school & $0.53^{* * *}$ & $-0.18^{* *}$ & Gender $-0.15^{*}$ & 0.39 \\
Perceived academic efficacy & $0.69^{* * *}$ & 0.09 & & \\
Disruptive behavior & $-0.49^{* * *}$ & 0.02 & Gender $0.22^{* *}$ & 0.49 \\
GPA & $0.28^{* *}$ & -0.12 & Gender $-0.21^{* *}$ & 0.20 \\
& & & Ethnicity $0.22^{* *}$ & \\
\hline
\end{tabular}

Note. $N=168$.

$* p<.05, * * p<.01, * * * p<.001$.

ing ego goals was found to be a significant negative predictor for some measures of well-being. In almost every case, the explained variance by both goals was equal to the sum of variance explained by each construct separately. And incidentally, this provides additional evidence for the orthogonality of the task and ego goal constructs noted earlier. None of the interaction terms of personal goals and GPA, and personal goals and perceptions of academic efficacy were significant.

\section{Part 3: Perceptions of the School Goal Emphasis and Student Well-Being}

A major objective of the study was to determine, at least in a preliminary way, whether the perceptions of the school environment could be considered as a factor in general well-being of students. Perceptions of the environment were conceptualized and indexed as perceptions of the degree of emphasis that the school placed on task and ego goals following a rationale presented by several researchers (e.g., Ames, 1992; Maehr, 1991; Maehr \& Midgley, 1991). In this regard a series of hierarchical multiple regression equations were computed in which, again, the psychological measures of well-being as well as GPA served as dependent variables. Dummy variables representing SES (free lunch $=0$, no-privileges $=1$ ), ethnicity (African Americans $=0$, Euro-Americans $=1)$, and gender $($ Girls $=0$, Boys $=1)$, were first entered. In a second step, perceived school emphasis on task and on ego goals were entered as a block into the equation.

Table 5 presents Beta values of perception of goals emphasized by the school as predictors of the well-being measures and of GPA after controlling for SES, ethnicity, and gender. Perceptions of the school as emphasizing task goals were a significant positive predictor for the academic related variables, and a significant negative predictor for perceptions of disruptive behavior. Perceptions of the school as emphasizing ego goals were a significant 
TABLE 5

Goals Perceived as Emphasized by School as Predictors of Well-Being

\begin{tabular}{|c|c|c|c|c|c|}
\hline & Task goals & Ego goals & \multicolumn{2}{|c|}{ Demographics } & $R^{2}$ \\
\hline Emotional tone & -0.01 & $-0.28 * *$ & & & 0.07 \\
\hline Peer relationships & 0.14 & -0.01 & Ethnicity & $-0.19 *$ & 0.07 \\
\hline Impulse control & 0.05 & $-0.23 * *$ & Gender & $-0.20 * *$ & 0.13 \\
\hline Affect at school & $0.18^{*}$ & $-0.23 * *$ & Gender & $-0.23 * *$ & 0.22 \\
\hline Perceived academic efficacy & $0.46^{* * *}$ & 0.01 & & & 0.24 \\
\hline Disruptive behavior & $-0.23 * *$ & $0.31 * * *$ & Gender & $0.25^{* * *} *$ & 0.33 \\
\hline \multirow[t]{2}{*}{ GPA } & $0.17 *$ & 0.02 & Gender & $-0.29 * * *$ & 0.15 \\
\hline & & & Ethnicity & $0.19 *$ & \\
\hline
\end{tabular}

Note. $N=168$.

$* p<.05, * * p<.01, * * * p<.001$.

negative predictor for emotional tone, impulse control, and affect at school, and a significant positive predictor for perceptions of disruptive behavior.

\section{Part 4: Ethnicity, Goals, and Well-Being}

A series of multiple regressions predicting well-being measures from personal and perceived achievement goals was run separately for the two main ethnic groups in the sample. Dummy variables of gender and SES were introduced in a first step. In a second step, the goal variables were entered as a block. The results in the case of both African American and Euro-American samples are presented separately for personal goals and perceived school goals emphases.

Personal goals. Results of the regressions of personal goals on well-being for both the African American and Euro American samples are presented in Table 6. Betas for SES and gender are reported when significant.

Holding personal task goals was a positive predictor of all the well-being measures except for "emotional tone" for the African American students, and "peer relationship" for the Euro-American students. Holding task goals was also a strong negative predictor for disruptive behavior for both groups. Holding ego goals was a negative predictor for some of the well-being measures for the African American students, specifically, for impulse control and affect at school, and a positive predictor for self-report of disruptive behavior. Personal goals were also significant predictors for GPA for the African American students and followed the same direction of prediction as above.

Perceived school emphases. Table 7 presents results of a comparable series of multiple regressions with perceived school emphases on goals as predictors of well-being and GPA for both the African American and the EuroAmerican samples. The pattern of results found in the case of perceived goal emphases was somewhat similar to that found in the case of personal goals 


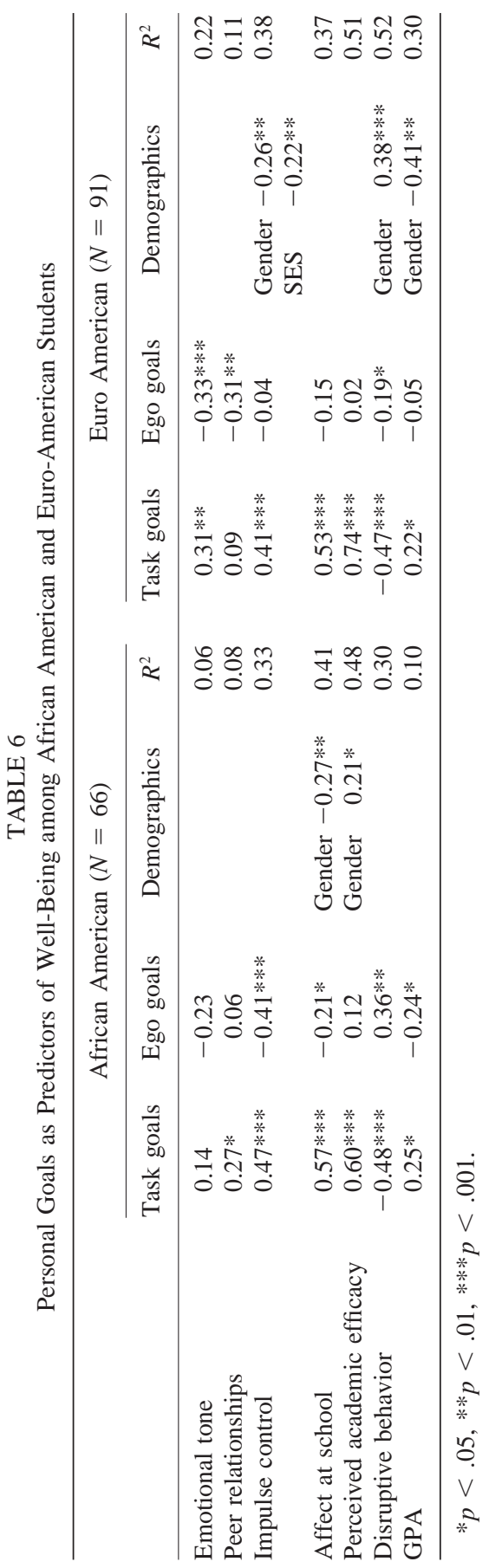


GOALS AND WELL-BEING

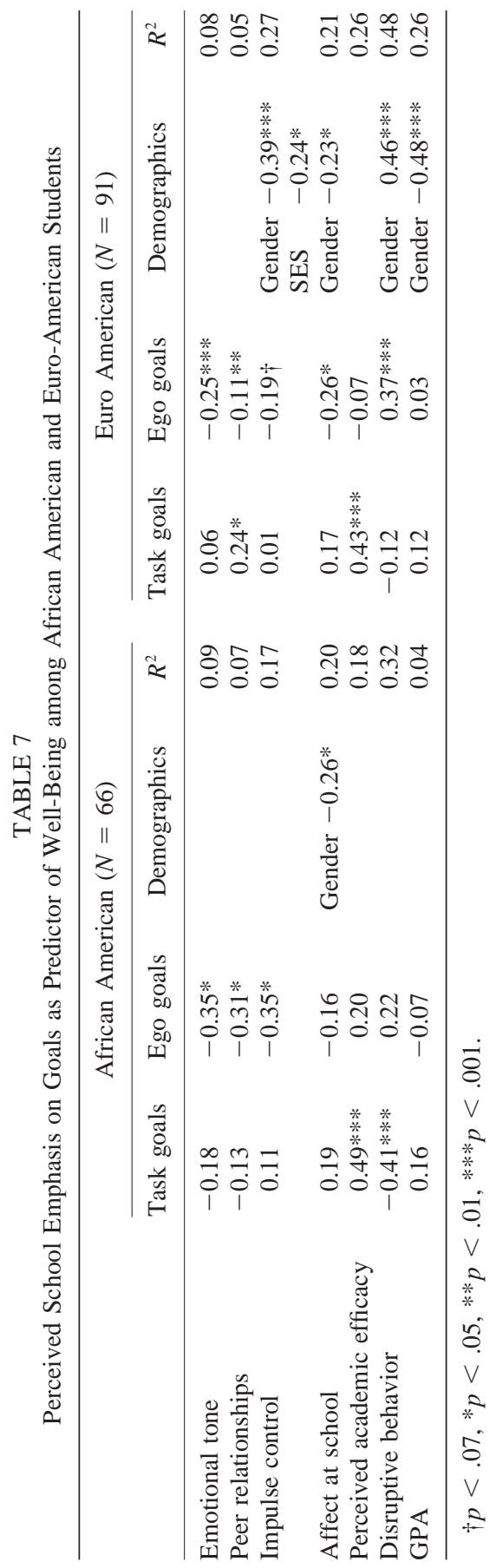


and well-being - though perhaps somewhat weaker. The perception that the school emphasized task goals was a positive predictor only for perceptions of academic efficacy and a negative predictor for perceptions of disruptive behavior. Perception of the school as emphasizing ego goals was a negative predictor for the three general well-being constructs for the African American students in the sample.

In summary, an overall pattern was observed in which holding personal task goals and perceiving the school as emphasizing task goals was related to positive academic behavior as well as to general indices of well-being. Holding personal ego goals and perceiving the school as emphasizing ego goals was related to negative academic and general indices of well-being. These relationships were weaker for the perceptions of goals emphasized in the school than for personal goals. This overall pattern was observed among the African American as well as among the Euro-American students in the sample. Differences were found between the two ethnic groups on particular indices of well-being that were related to the goal measures. While not a focus of the present analysis, a note can be made concerning the finding that gender seems to be more strongly associated with differentiating experiences among Euro-American than among African American boys and girls.

\section{Part 5: Modeling African American and Euro American Students' Well-Being}

The results reported thus far suggest a general pattern in which the perceived school environment and personal goals figure strongly in adolescent well-being in school settings. Possibly the perceptions of the school is a major factor in the goals students adopt and with that also in the adaptive behavior and sense of well-being they exhibit. That general pattern of events was outlined earlier in Fig. 1 and was supported by Roeser et al. (1996). Implied there is that school goal emphases not only encourage the adoption of particular personal goals but by doing so influence self-efficacy. Further, the "effects" on self-efficacy are hypothesized to mediate goal effects on action, thought and affect more generally — and presumably well-being more specifically. There is basis for making such an argument-at least in the case of Euro-American samples. However, in light of the discussion concerning the possible different role of self-processes among African American students, one cannot be sure that the same model applies equally to both samples, especially in regard to the role that sense of self might play.

This is a self-evidently important issue, one that must be considered in interpreting the present results. Of course, the correlational nature of the data makes it impossible to provide any definitive test of the role of perceived academic efficacy in mediating goal effects in the present instance. However, a second best alternative is available: path analysis. Accordingly, we pro- 
ceeded to test the degree to which the Anderman-Maehr model would fit the results obtained with the Euro-American and African American samples.

A series of path analyses using LISREL 8 (Jöreskog \& Sörbom, 1994) was conducted. The relatively small number of subjects, especially when divided to the two ethnic groups, prevented us from testing the measurement part of the model. Nevertheless, a test of the structural model can provide some insights into possible differences in the conceptualization of the processes occurring within the two groups.

As a first step, the goodness-of-fit of the Anderman and Maehr model (Fig. 1) was examined in the case of the combined samples $(N=168)$. The model was tested separately for each of the dependent variables. Overall, the analysis indicated that perception of goals emphasized in the school have indirect effects on the dependent variables through perceived academic efficacy and through personal goals and perceived academic efficacy — a finding also supported by Roeser et al. (1996) for school-related outcomes. The analyses also supported, however, direct effects of students' perceptions of school goal emphases on perceived academic efficacy and on the outcome variables. This indicates that experiences in the environment might have an independent influence on students' affect and behavior in addition to the indirect effect through goals and perceived efficacy.

More importantly, however, in comparing African American and EuroAmerican samples on this model it was found that the model was not an equally good fit for both samples. While the suggested model was a very good fit for the Euro-American students, it was quite a bad fit for the African American students. Figure 2 presents the modified Anderman and Maehr model, with perceptions of disruptive behavior as the dependent variable ${ }^{4}$ that seems to fit the Euro American sample better than the African American sample.

We hypothesized that the findings reviewed by Graham (1994) and others (e.g., Covington, 1992) point to African American students' perceived academic efficacy as having a more stable nature than that of Euro-American students. Furthermore, we hypothesized that while Euro-American as well as African American students' perceptions of the school goal emphases will have an influence on their perceived academic efficacy - albeit to different degrees-African American students will be less attentive to these perceptions and that their perceived academic efficacy will tend to be more influential in the personal goals they adopt. Figure 3 presents a model that depicts such a process and which seems to fit the African American sample better

\footnotetext{
${ }^{4}$ Fit indices of the path models involving other well-being variables for the Euro-American and African American students were similar to those reported in Figs. 2 and 3. For reasons of brevity and because the path analyses were not the central feature of the paper, we present only one model with one variable.
} 


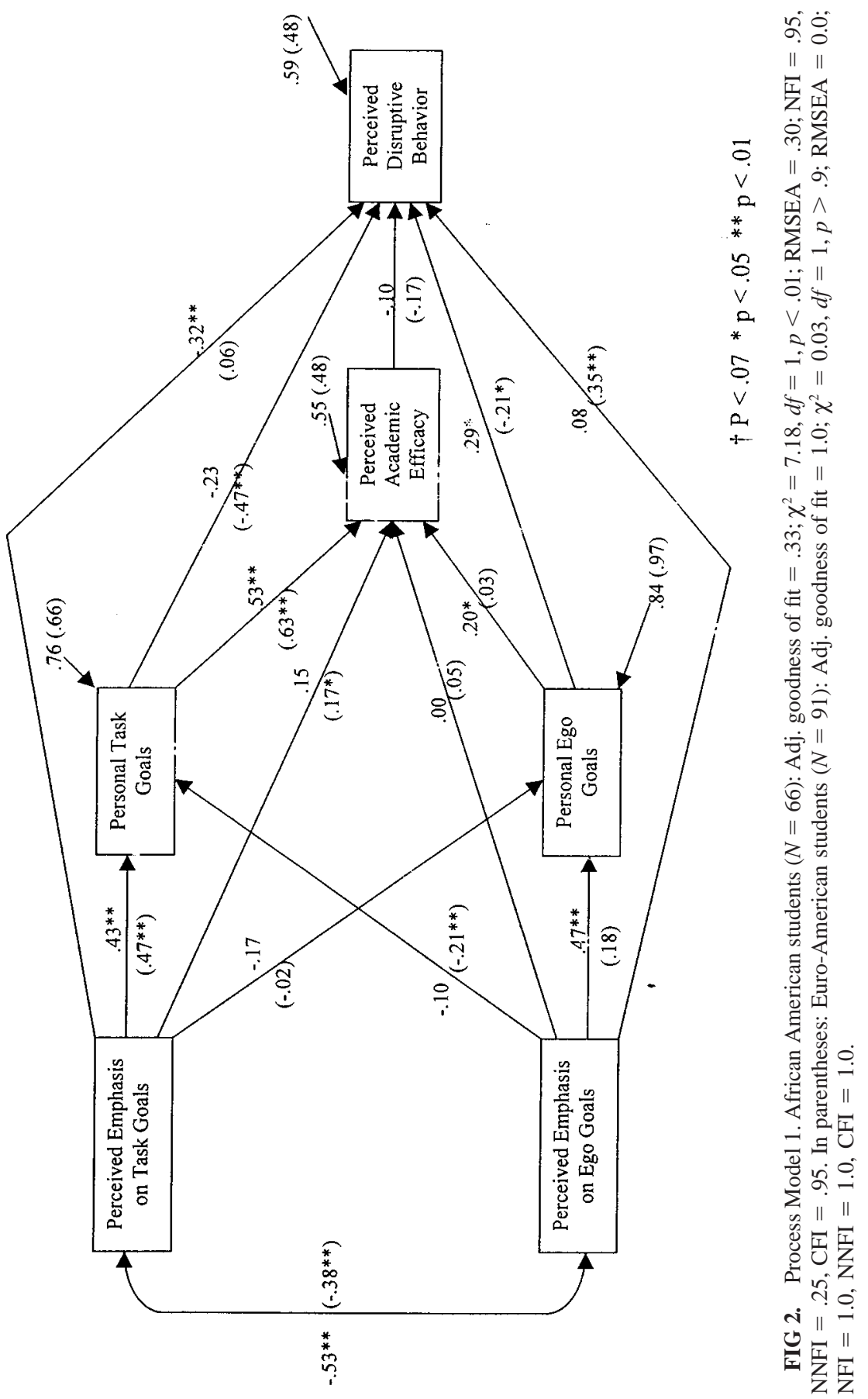




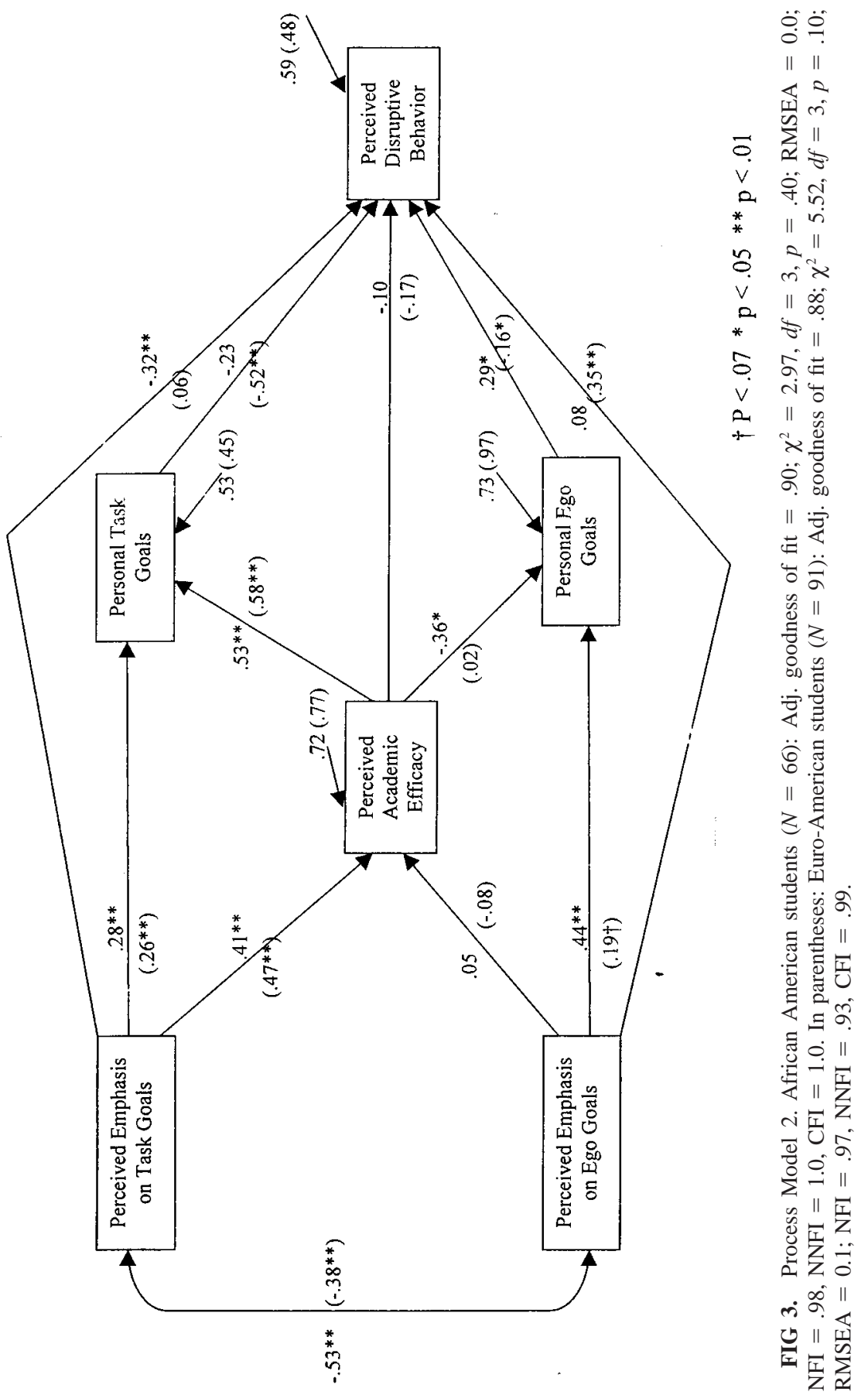


than the first model. Caution should be taken in interpreting these findings due to the small $N$; however, the second model (process model 2; Fig. 3) exhibits several points of difference from Process Model 1 (Fig. 2) that merit attention. Clearly, self-efficacy is more salient and an independently determining factor in Process Model 2. That is, while clearly important in both models, in Process Model 2 academic self-efficacy does not appear to be a function of personal goals held, though it is apparently evoked by school emphasis on task goals. While influenced by school goal emphasis, it is portrayed as determinative of personal goals adopted.

\section{DISCUSSION}

\section{Goal Orientations and Well-Being}

Heretofore, the study of goal orientations has been largely confined to a focus on motivation and achievement. The present results open up a new possibility: Goal orientations likely affect emotional well-being as well. Pursuing task goals was found to have a significant positive relationship with all indices of well-being, as well as with perceptions of academic efficacy and GPA. Pursuing ego goals was found to have a significant negative relationship with two of the general indices of well-being, and with affect at school. Findings suggest that goal orientation is related to emotions and cognitions that not only contribute to effective learning but which also relate to psychological well-being more generally. Task goals are more likely to facilitate learning and school achievement. For this, and perhaps other reasons as well, task goals also contribute to psychological well-being. While these findings could be and in fact were anticipated on the basis of generalizations and extrapolations from previous research (cf. Covington, 1992), firm and replicable support specific to goal theory per se has not been widely reported-if indeed it has been directly sought.

Perhaps of greater interest is the initial, but not unimportant, suggestion that well-being might stem from perceptions of task and ego goal emphases reflected in school policies and practices. In general, the effects of perceived emphasis on task goals seemed to be weaker or more limited in nature than those associated with a perceived emphasis on ego goals. Of particular interest, is that both task (negatively) and ego (positively) goal emphases were associated with report of disruptive behavior. There are vagaries in the findings, of course. The relations of perceptions of ego goal emphasis and adoption of ego goals with well-being were not as ubiquitous as those of task goals. Furthermore, some differences were found in these relations between the two ethnic groups. However, in the main, the results of the analyses, including the path models, support the notion that the school environment as perceived by students, figures significantly and importantly in the sense of 
well-being and can contribute to behavior and affect that facilitates a positive orientation toward life generally.

In sum, there appears to be a double reason for pursuing task, and avoiding ego goals. Equally, if not even more interesting, there seems to be a double advantage when schools avoid being seen as emphasizing ego goals - and are viewed as emphasizing task goals. Task goals are associated with positive learning and positive feelings about oneself and one's world. Emphasis on ego goals seems likely to create problems in learning as well as in the life of the person more generally. This may be a particularly interesting and important issue in the life of the young adolescent who is characteristically conscious of self, often worried about ability, and perhaps especially inclined toward social comparison. Schools that emphasize and exacerbate the focus given to the ego are likely to create not only problems in learning, but also "behavioral problems.', And more generally, they are likely to undermine emotional well-being. Of course, one study does not a principle make, in particular when one deals only with students' perceptions. But as the results confirm what might have been anticipated from previous work on goal orientations, they should be taken seriously in considering the effects of school practices on the life of young adolescents.

\section{Goals, Well-Being, and Ethnicity}

Little if any research on goals has considered possible differences in processes in the case of African Americans and Euro-Americans (cf. Graham, 1994; Pintrich \& Schunk, 1996). For both practical and theoretical reasons, this is surprising. It also represents a limitation of the current literature that this study was designed in part to address.

Generally, the regression analyses results indicated similar patterns of relationships for Euro- and African Americans. Personal task goals were positively associated with almost all of the well-being measures. Similarly, personal ego goals were negatively associated with many of the measures of well-being. And, for both groups, the school emphases were not so consistently related to well-being as were the personal goals. For both groups, then, the presence of task goals tends to be positive, generally supportive of psychological well-being. In contrast, ego goals tend to be associated with a negative pattern of psychological well-being. What is particularly interesting, however, is the possibility emerging in the path models that different processes might be involved.

Initially, we set out to test a preliminary model (Fig. 1) in which any relations with well-being are mediated by perceived academic efficacy. Implied in this model are several, inter-related hypotheses. Specifically, perceived goal emphases in the school influence students to adopt comparable personal goals. The adoption of personal task goals likely leads to enhanced 
perceived efficacy; the adoption of ego goals likely leads to diminished perceived efficacy. Perceived academic efficacy in turn should be related to a wide range of indices of well-being. And in any event, a critical factor is how perceptions of school emphases figure into the conception of self. In the case of Euro-Americans, this general model works fairly well, except that perceptions of school and personal goals apparently have separate effects. This model, however, fails badly in the case of African Americans. It fails largely because of the projected place of perceived efficacy in the model.

An alternative model (Fig. 3) was found to account better for the African American students in this sample. As the sample is small, not much can be assumed from the present results about the role of perceived efficacy for African American students. Overall the path analyses have implied a complex picture that only future research can resolve. However, some directional clarity might be found in the finding that, as others have suggested (e.g., Graham, 1994), self-hood, plays a different role among African American adolescents than among Euro-American samples. Regardless, the school seems to be a persistent factor of influence and the supported model allows some speculations. First, both school goal emphases and self-efficacy appear to combine in leading to the adoption of personal goals. Further, it seems that school task goal emphasis and self-efficacy combined are likely to lead to the adoption of personal task goals - for both African American and EuroAmerican groups. At distinct variance from this pattern are the findings in the case of ego goals. School ego goal emphasis is related to personal goals held or adopted-but is unrelated to self-efficacy. And, while self-efficacy is strongly and positively related to adopting or holding personal task goals, the results are mixed in the case of ego goals: Related in the case of African Americans and unrelated with Euro-Americans.

Generally, then, the results present a picture in which task goal emphasis in the school is associated with self-efficacy, the adoption of personal task goals and ultimately a general sense of well-being - for both African American and Euro-American students. School ego goal emphasis is associated with the adoption of personal ego goals in the case of both ethnic groupsand, of course, in turn related to a lowered sense of well-being. The thrust of these results is that a school that is perceived to emphasize task goals is definitely to be preferred for both groups.

\section{Limitations and Future Research}

While we deem the findings of the present study telling, obviously caution in adopting them is warranted due to several limitations. First, the relatively small size of the sample prevents us from making stronger claims about the generalizability of these findings. Second, the correlational nature of the data, which were collected at one time point, limits the interpretation with regard to the processes involved. Nevertheless, extrapolations from the data, when 
supported by theory, can provide suggestions for directions in future investigations. Third, the lack of more adequate socio-economic information prevented us from examining more thoroughly the possible influence of this factor on the relations examined. Finally, the small sample as well as the focus of the paper did not allow a thorough examination of gender effects on the processes examined. Interestingly, the regression results suggested that gender seemed to play a more significant differentiating role for relations among the Euro-American than among the African American students. Nevertheless, African American adolescents are not a homogeneous group. Gender is, unquestionably, an important factor in determining different experiences in school as well as out of school and should be paid due attention.

With these in mind, however, we see promise in the directions that these findings suggest. Conceptualizing the appraisals of school environment in goal emphasis terms could be, we believe, a useful way of examining the role that such environments play in adolescents' lives. That is not new of course. Considerable work has already suggested that task and ego goal emphases in school affect motivation and achievement. What we have in the present results is a basis for suggesting that school goal emphases that positively affect motivation and achievement also affect adolescent well-being more generally. The patterns of the findings in this regard move us further along the path of proposing how school contexts not only are structured but how they should be constructed, at least for young adolescents, perhaps younger and older persons more generally. It is particularly significant, we feel, that very similar results in this regard were found for two different ethnic groups. Of course, these findings should be replicated and certain of the interrelationships explored further. But a beginning of importance in this regard, we feel, has been made.

\section{APPENDIX}

\section{Perceptions of School Goal Emphases Scales}

\section{Perceptions of Emphasis on Ego Goals}

In this school, teachers are always talking about the honor roll and the honor society.

In this school, teachers treat kids who get good grades better than other kids.

In this school, only a few kids get praised for their school work.

In this school, teachers only care about the smart kids.

In this school, we are encouraged to compete against each other for grades.

This school has given up on some of its students.

In this school, special privileges are given to students who get the highest grades. 


\section{Perceptions of School Emphasis on Task Goals}

In this school, teachers believe all students can learn.

In this school, every student can be successful.

In this school, understanding the work is more important than getting the right answers.

In this school, mistakes are okay as long as we are learning.

In this school, teachers think how much you learn is more important than tests scores or grades.

Teachers in this school want students to really understand their work, not just memorize it.

Trying hard counts a lot in this school.

In this school, we are given a chance to do interesting and creative work.

\section{Personal Achievement Goals Scales}

\section{Personal Ego Goals}

I would feel good if I was the only one who could answer the teacher's questions in class.

I would like to show my teachers that I'm smarter than the other kids. I would feel successful in school if I did better than the other students in my classes.

I'd like to show my parents that I'm smarter than the other kids in my classes.

I wish we had school work that would let me show I'm smart.

\section{Personal Task Goals}

Understanding the work in school is more important to me than the grade I get.

I like school work that I'll learn from even if I make a lot of mistakes. The main reason I do my work in school is because I like to learn.

I like school work the best when it really makes me think.

I feel most successful in school when I learn something I didn't know before.

It doesn't matter to me if other students do better than I do, as long as I am learning.

\section{General Well-Being Scales}

\section{Emotional Tone}

I feel nervous most of the time. (reversed)

I feel that I am not as good as most people I know. (reversed)

Most of the time I am happy.

My feelings are easily hurt. (reversed) 
I feel relaxed under normal circumstances.

I feel empty emotionally most of the time. (reversed)

I am so very nervous. (reversed)

I feel so very lonely. (reversed)

I enjoy life.

Very often I think that I am not at all the person I would like to be. (reversed)

I frequently feel sad. (reversed)

\section{Peer Relationships}

Other kids find me a bore. (reversed)

I usually feel out of place at picnics and parties. (reversed)

I think that other people just do not like me. (reversed)

I find it very difficult to establish new friendships. (reversed)

I find it extremely hard to make friends. (reversed)

I would rather be alone than with kids my age. (reversed)

I think that other kids find me attractive.

Being together with other people gives me a good feeling. I do not have a particularly difficult time making friends.

I enjoy most parties I go to.

\section{Impulse Control}

I "lose my head" easily. (reversed)

I become violent if I don't get my way. (reversed)

Even under pressure I manage to remain calm.

I keep an even temper most of the time.

I am a calm person.

Usually I control myself.

There are people that I will never forgive for things they have done. (reversed)

Sometimes I do things that I know I shouldn't but I can't stop myself. (reversed)

\section{School-Related Well-Being Scales}

\section{Affect at School}

Most of the time, being in school puts me in a good mood.

I like being in school.

I am happier when I am at school than when I am not at school.

I am often angry when I'm at school. (reversed)

I often feel frustrated when I am doing school work. (reversed)

School often makes me feel bad. (reversed)

I often feel bored in school. (reversed) 


\section{Perceived Academic Efficacy}

I'm certain I can master the skills taught in school this year.

I can do even the hardest school work if I try.

If I have enough time, I can do a good job on all my school work.

I can do almost all the work in school if I don't give up.

Even if the work in school is hard, I can learn it.

I'm certain I can figure out how to do the most difficult school work.

\section{Self-Report of Disruptive Behavior}

Teachers often get upset with me.

I don't make friends with people that always behave nice in class.

I think that people who annoy the teachers are cool.

I get into trouble at school more than most kids.

I sometimes make fun of students who do very well.

\section{REFERENCES}

Aiken, L. S., \& West, S. G. (1991). Multiple regression: Testing and interpreting interactions. Newbury Park, CA: Sage.

Ames, C. (1992). Classrooms: Goals, structures, and student motivation. Journal of Educational Psychology, 84, 261-271.

Ames, C., \& Archer, J. (1988). Achievement goals in the classroom: Student learning strategies and motivation processes. Journal of Educational Psychology, 80, 260-267.

Anderman, E. M., Maehr, M. L., \& Midgley, C. (in press). Declining motivation after the transition to middle school: Schools can make a difference. Journal of Research and Development in Education.

Anderman, E. M., \& Maehr, M. L. (1994). Motivation and schooling in the middle grades. Review of Educational Research, 64, 287-309.

Carnegie Council on Adolescent Development. (1989). Turning points: Preparing American youth for the 21st century. (Report of the Task Force on Education of Young Adolescents). New York: Author.

Covington, M. V. (1992). Making the grade: A self-worth perspective on motivation and school reform. New York: Cambridge Univ. Press.

Dweck, C. S. (1986). Motivational processes affecting learning. American Psychologist, 41, 1040-1048.

Dweck, C. S., \& Leggett, E. L. (1988). A social-cognitive approach to motivation and personality. Psychological Review, 95, 256-273.

Eccles, J. S., Midgley, C., Wigfield, A., Miller Buchanan, C., Reuman, D., Flanagan, C., \& Mac Iver, D. (1993). Development during adolescence: The impact of stage-environment fit on young adolescents' experiences in schools and in families. American Psychologist, 48, 90-101.

Graham, S. (1994). Motivation in African Americans. Reviews of Educational Research, 64, $55-117$.

Jöreskog, K. G., \& Sörbom, D. (1994). LISREL 8.12A, Chicago, IL: Scientific Software, Inc. Kaplan, A., \& Maehr, M. L. (1997). School cultures. In H. Walberg \& G. Haertel (Eds.), 
Psychology and educational practice (Chapter 16, pp. 342-355). Berkeley, CA: McCutchan.

Kazdin, A. E. (1993). Adolescent mental health: Prevention and treatment programs. American Psychologist, 48, 127-141.

Krug, S. E. (1989). Leadership and learning: A measurement-based approach for analyzing school effectiveness and developing effective school leaders. In M. L. Maehr \& C. Ames (Eds.), Advances in motivation and achievement: Motivation enhancing environments (Vol. 6. pp. 248-274). Greenwich, CT: JAI Press Inc.

Lazarus, R. S. (1993). From psychological stress to the emotions: A history of changing outlooks. Annual Review of Psychology, 44, 1-21.

Maehr, M. L. (1991). The "psychological environment" of the school: A focus for school leadership. In P. Thurston \& P. Zodhiates (Eds.), Advances in educational administration, (Vol. 2, pp. 51-81). Greenwich, CT: JAI Press Inc.

Maehr, M. L., \& Fyans, L. J. (1989). School culture, motivation, and achievement. In M. L. Maehr \& C. Ames (Eds.), Advances in motivation and achievement: Motivation enhancing environments (Vol. 6, pp. 215-247). Greenwich, CT: JAI Press Inc.

Maehr, M. L., \& Midgley, C., \& Colleagues (1996). Transforming school cultures. Boulder, CO: Westview Press.

Maehr, M. L., \& Midgley, C. (1991). Enhancing student motivation: A schoolwide approach. Educational Psychologist, 26, 399-427.

Meece, J. L. (1991). The classroom context and students' motivational goals. In M. L. Maehr \& P. R. Pintrich (Eds.), Advances in motivation and achievement (Vol. 7, pp. 261-285). Greenwich, CT: JAI Press Inc.

Meece, J. L., Blumenfeld, P. C., \& Hoyle, R. H. (1988). Students' goal orientations and cognitive engagement in classroom activities. Journal of Educational Psychology, 80, 514523.

Meece, J. L., \& Holt, K. (1993). A pattern analysis of students' achievement goals. Journal of Educational Psychology, 85, 582-590.

Midgley, C., Anderman, E., \& Hicks, L. (1995). Differences between elementary and middle school teachers and students: A goal theory approach. Journal of Early Adolescence, 15, 90-113.

Midgley, C., Kaplan, A., Middleton, M., Maehr, M. L., Urdan, T., Anderman, L. H., Anderman, E., \& Roeser, R. (1998). The development and validation of scales assessing students' achievement goal orientations. Contemporary Educational Psychology, 23, 113131.

Midgley, C., Maehr, M. L., \& Urdan, T. C. (1993). Patterns of adaptive learning survey (PALS). University of Michigan.

Nolen, S. B. (1988). Reasons for studying: Motivational orientations and study strategies. Cognition and Instruction, 5, 269-287.

Nolen, S. B., \& Haladyna, T. M. (1990). Personal and environmental influences on students' beliefs about effective study strategies. Contemporary Educational Psychology, 15, 116130.

Ogbu, J. U. (1992). Understanding cultural diversity and learning. Educational Researcher, 21, 5-14.

Ogbu, J. U. (1981). Origins of human competence: A cultural-ecological perspective. Child Development, 52, 413-429.

Petersen, A. C., Schulenberg, J. E., Abramowitz, R. H., Offer, D., \& Jarcho, H. D. (1984). A 
self-image questionnaire for young adolescents (SIQYA): Reliability and validity studies. Journal of Youth and Adolescence, 13, 93-111.

Pintrich, P. R., Marx, R. W., \& Boyle, R. A. (1993). Beyond cold conceptual change: The role of motivational beliefs and classroom contextual factors in the process of conceptual change. Review of Educational Research, 63, 167-199.

Pintrich, P. R., \& Schunk, D. (1996). Motivation in education: Theory, research, and applications. Englewood Cliffs, NJ: Prentice Hall.

Roeser, R. W., Midgley, C., \& Urdan, T. C. (1996). Perceptions of the school psychological environment and early adolescents' psychological and behavioral functioning in school: The mediating role of goals and belonging. Journal of Educational Psychology, 88, 408422.

Steele, C. M. (1992, April). Race and schooling of black Americans. The Atlantic Monthly, $68-78$.

Steele, C. M., \& Aronson, J. (1995). Stereotype threat and the intellectual test performance of African Americans. Journal of Personality and Social Psychology, 69, 797-811.

Urdan, T. (1997). Achievement goal theory: Past results, future directions. In M. L. Maehr \& P. R. Pintrich (Eds.), Advances in motivation and achievement (Vol. 10). Greenwich, CT: JAI Press.

Urdan, T. C., \& Maehr, M. L. (1995). Beyond a two-goal theory of motivation and achievement: A case for social goals. Review of Educational Research, 65, 213-243.

Veit, C. T., \& Ware, J. E. (1983). The structure of psychological distress and well-being in general populations. Journal of Consulting and Clinical Psychology, 51, 730-742.

Wolters, C., Garcia, T., \& Pintrich, P. R. (1992). Assessing early adolescents' school competence and commitment. Unpublished manuscript, University of Michigan. 